\title{
ScIDice
}

\author{
International Journal of Dentistry and Oral Science (IJDOS) \\ ISSN: 2377-8075
}

\section{Association of Handedness and Maximum Voluntary Bite Force on Respective Side of Oral Cavity}

Research Article

Danish Altaf ${ }^{*}$, Muhammad Sohaib Nawaz ${ }^{2}$, Muhammad Hassan ${ }^{3}$, Arooj ul Hassan ${ }^{4}$, Muhammad Haseeb $^{5}$, Aqil Malik ${ }^{6}$

${ }^{1}$ Post graduate resident, Department of Prosthodontics, University college of Medicine and Dentistry, University of Lahore, Pakistan.

${ }^{2,6}$ Assistant Professor, Department of Prosthodontics, University college of Medicine and Dentistry, University of Lahore, Pakistan.

${ }^{3}$ Assistant Professor, Department of Dental Materials, University college of Medicine and Dentistry, University of Lahore, Pakistan.

${ }^{4}$ Assistant Professor, Department of Community and Preventive Dentistry, University college of Medicine and Dentistry, University of Lahore, Pakistan.

${ }^{5}$ Assistant Professor, Department of Periodontology, University college of Medicine and Dentistry, University of Lahore, Pakistan.

\section{Abstract}

Introduction: The aim of the study was to explore the difference between handedness and bite force among general population. Method: Bite force was recorded with an Occlusal Bite force meter (GM-10 Nagano Keiki Japan). A mean of three left sided and a mean of three right sided maximum voluntary bite forces were calculated and a final mean of the two were taken to find out the Mean Maximum Voluntary Bite force. The data was entered and analyzed in SPSS version 25.0. As descriptive statistics, percentage of gender distribution was calculated. Later on, Paired sample $t$ test and independent sample $t$ test was used to explore the bite force difference among right and left handed participants.

Results: Paired sample $t$ test used to calculate between group difference of Bite Force which was found to be significant $(t=2.895$, $\mathrm{P}=.005)$. The results of independent sample $t$ test revealed a significant difference between the handedness and the average force bite from left side of mouth $(\mathrm{t}(2,68)=-3.08, \mathrm{P}=.003)$. The results for the comparison of average bite force from right side of mouth and handedness was also found significant $(\mathrm{t}(2,68)=2.36, \mathrm{P}=.02)$.

Conclusion: The study explored the difference of handedness with the bite force which was found to be significant. The results explained that right handed people have higher bite force at right side of mouth on chewing whereas left handed people apply more force while biting with left side of mouth as compared to right side. This was the new finding explored by performing this study.

\section{Introduction}

For language, the major imperative behavioral irregularity is handedness because of its close relationship with the brain specialization. Handedness can be seen in 3 levels, i-e., right handedness, left handedness and both right and left handedness (mixed). The primary minority group categorized around the globe is the group of Left-handers and at several times they face disadvantaged situations due to left handedness paralleled to right handers. Numerous studies demonstrated association between left-handedness and different health problems ranging from learning disorders to breast cancer and decreased longevity. This paper is based on the concept that there might be some difference between the handedness and bite force.
Dissemination of handedness in a populace possess structures of directional irregularity in which non-racemic combination of two kinds of laterality is present [1]. In human around the globe, there is a Harmonious inclination for preferring the right hand as the prevalence of left handed people is around $10 \%$ of population in most of the cultures [1-4]. It is suggested from this fact that the change to the right has been determined on general preconception towards right hand as compared to unintentional inclinationtowards left hand $[1,2]$. Numerous authors proposed that the evolution of right-handedness is based on convenience of using right hand for various activities as carrying and soothing of a baby or for eating food $[5,6]$.

Occlusal Bite force is the interocclusal force that is produced when the jaw is closed under the effect of jaw muscles as a result of the coordination between different components of the

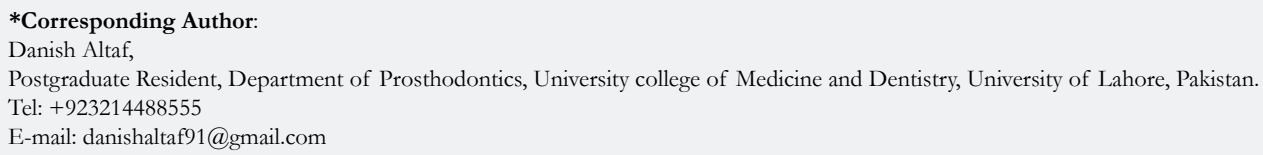

Citation: Danish Altaf, Muhammad Sohaib Nawaz, Muhammad Hassan, Arooj ul Hassan, Muhammad Haseeb, Aqil Malik. Association of Handedness and Maximum Voluntary Bite Force on Respective Side of Oral Cavity. Int J Dentistry Oral Sci. 2020;7(11):972-975. doi: http://dx.doi.org/10.19070/2377-8075-20000193

Copyright: Danish Altaf 2020. This is an open-access article distributed under the terms of the Creative Commons Attribution License, which permits unrestricted use, distribution and reproduction in any medium, provided the original author and source are credited. 
masticatory system i.e. muscles, bones and teeth [1]. Occlusal bite force is frequently used to evaluate masticatory function because it reflects the maximum voluntary contraction of the masticatory muscles [2]. Masticatory muscles more importantly Masseter, Temporalis and Medial Pterygoid plays an important role in the closure of the jaw. Maximum voluntary bite force (MVBF) is the capacity of the mandibular elevator muscles to perform a maximum strain of mandibular teeth against the maxillary teeth1-3. MVBF magnitude is influenced by age, gender, face form, occlusion, periodontal and gingival problems, missing teeth, pulp related problem, jaw muscle cross-sectional area, craniofacial morphology and temporomandibular disorders [1, 4-6].

At its peak level, Maximum Bite Force was recorded in first molar region [7]. Among healthy adults with natural teeth, the unilateral MVBF measurements in the molar region averages between $300 \mathrm{~N}$ to $600 \mathrm{~N}$ [8]. The average bite force in males from 13 to 40 years is 374 . $\pm 30.75 \mathrm{~N}$ and average bite force in females of age 13 to 40 years is $257 \pm 31 \mathrm{~N}$ [8]. The mean bite force at this age is 315.5 $\pm 30.87 \mathrm{~N}$ [8]. The average increase in the rate of bite force on the permanent molars in children has been reported to be $23 \mathrm{~N}$ per year from 7 years to early twenties. All correlations between MVBF and age reduces between 26 and 41 year and then forces decrease after the age of 45 years [8]. Generally there has been a gradual decrease in average bite force with the time. Discrepancies in relation to the maximum bite force were found on regional bases, that white western population have less average bite force than Eastern population which in turn have less average bite force than Black African [8]. The rural area people generally have higher average bite force than urban area [7]. Food choice is one of the major known cause of these differences at regional levels. Soft food consumption resulting in lesser average bite force [7]. There are numerous study available on average bite force, but no literature was cited related to the relationship between the left, or right handedness with the side of molar region with higher average force bite. The aim of the study was to explore the difference between handedness and bite force among general population.

\section{Material and Methods}

This quantitative study was of crossectional in nature. The research was approved by the Ethics Committee of the Fatima Memorial College of Medicine and Dentistry Lahore. Sample size was estimated as 72 subjects. Both genders were included in the study. The subjects signed an informed consent to participate in the study before data collection.

The subjects had a neutral occlusion (Class I molar relationship) with balanced facial profiles, a symmetric appearance in the frontal view, harmoniously shaped competent lips, and absence of previous orthodontic treatment. They had normal healthy teeth (intraoral examination reveal no caries, mobility, periodontitis or any pulp related pathology) and a full natural complement of teeth from 2nd molar to 2 nd molar both in maxilla and mandible. None of the subjects had craniofacial anomalies or systemic muscle or joint disorders. Morphological examination verified the neutral occlusal relationship (both canines and molars were Angle Class I), the presence of all permanent teeth, except third molars, and the absence of any dental malocclusion, even minor rotations. The evaluation of inclusion criteria for each subject was conducted by a Prosthodontist using a mouth mirror and artificial lighting.

The instrument used for measuring bite force in a portable occlusal force gauge (GM10; Nagano Keiki, Tokyo, Japan). The instrument consisted of a hydraulic pressure gauge and a biting element $(17 \mathrm{~mm}$ in width and $5.4 \mathrm{~mm}$ in height) made of a vinyl material encased in a disposable plastic tube (Figure 1,2).

Each tube was used for one person after whom the device was cleaned with a cloth moistened with alcohol. The measuring range of the instrument was from 0 to $1000 \mathrm{~N}$ with an accuracy of \pm 1 N. Bite force was displayed digitally. All measurements were made with the subjects seated with back unsupported, looking forward and head in unsupported natural position (Figure 3).

Measurements of MVBF were undertaken during a single session for each subject, using the instrument. It was measured unilaterally on both the left and right sides of the jaw in the 2nd pre molar and first molar region. The maximum bite force was measured three times on each side with an interval of minimum 3 minutes. Mean of each side was recorded separately and later an average of both the means were taken to record MVBF. None of the subjects experienced any discomfort or pain during biting on the instrument.Data was entered in SPSS version 25.0 and independent sample $t$ test was used to analyze the effect of handedness on the average force bite.

Figure 1.

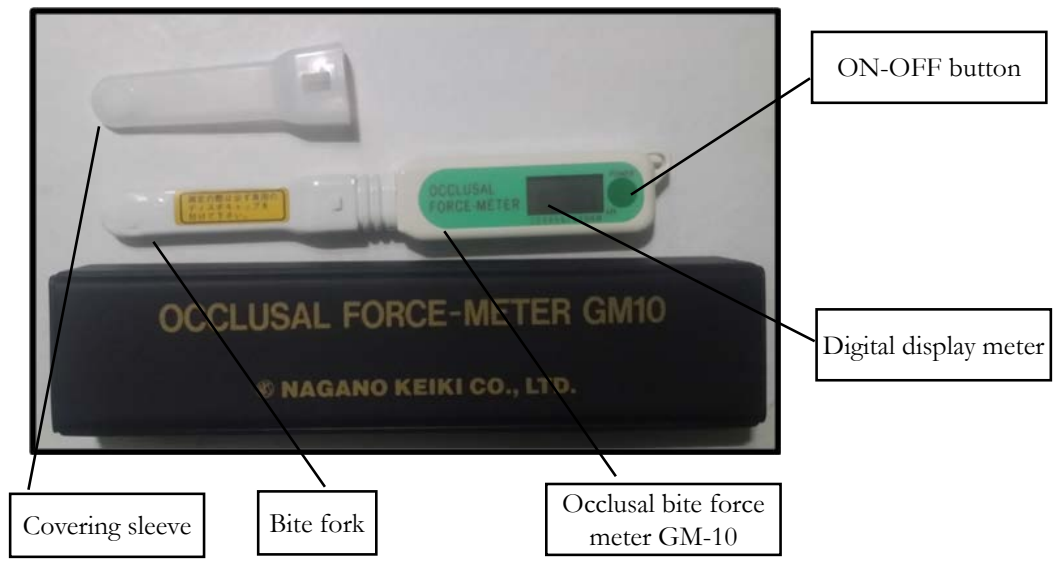


Figure 2.

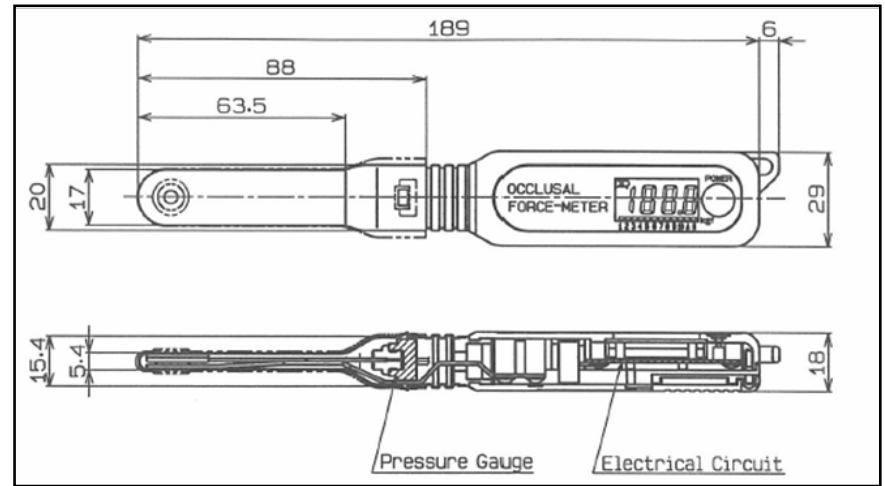

Figure 3.

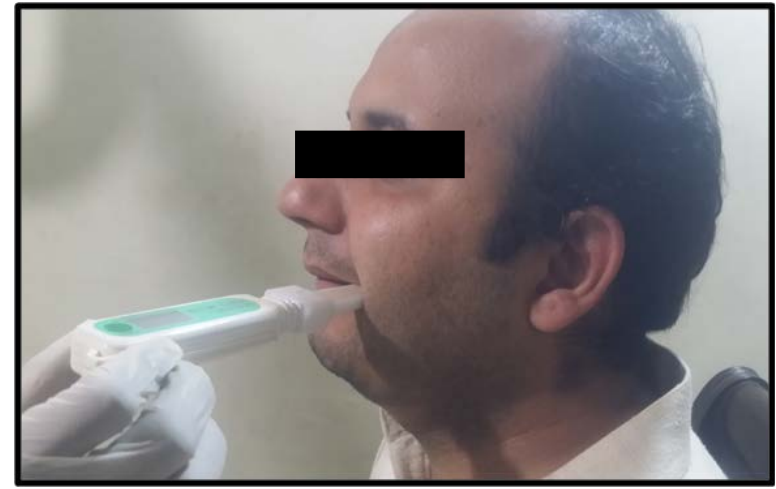

Table 1. Between group difference of Bite force.

\begin{tabular}{|c|c|c|c|c|c|c|}
\hline & Mean & $\begin{array}{c}\text { Std. } \\
\text { Deviation }\end{array}$ & \multirow{2}{*}{$\mathbf{t}$} & \multirow{2}{*}{ Sig. } & \multicolumn{2}{|c|}{$\begin{array}{c}\text { 95\% Confidence } \\
\text { Interval of the Difference }\end{array}$} \\
\cline { 6 - 7 } & & & & Lower & Upper \\
\hline Bite Force from Right Side & 593.569 & 136.586 & \multirow{2}{*}{2.895} & 0.005 & 23.383 & 126.921 \\
\hline Bite Force from Left Side & 518.416 & 161.475 & & & \\
\hline
\end{tabular}

Table 2. Comparison of Average Bite Force with Handedness.

\begin{tabular}{|c|c|c|c|c|c|c|c|c|}
\hline & \multicolumn{2}{|c|}{ Right Handedness } & \multicolumn{2}{|c|}{ Left Handedness } & \multirow{2}{*}{$\mathbf{2}$} & \multirow{2}{*}{ sig. } & \multicolumn{2}{|c|}{$\begin{array}{c}\text { 95\% confidence inter- } \\
\text { val of the difference }\end{array}$} \\
\cline { 2 - 5 } & $\begin{array}{c}\text { Mean } \\
\text { (N=36) }\end{array}$ & $\begin{array}{c}\text { Std. } \\
\text { Deviation }\end{array}$ & $\begin{array}{c}\text { Mean } \\
\text { (N=36) }\end{array}$ & $\begin{array}{c}\text { Std. } \\
\text { Deviation }\end{array}$ & & & Lower & Upper \\
\hline $\begin{array}{c}\text { Bite Force from } \\
\text { right side }\end{array}$ & 633.33 & 142.071 & 554.805 & 120.705 & 2.495 & 0.015 & 15.559 & 139.496 \\
\hline $\begin{array}{c}\text { Bite Force from } \\
\text { left side }\end{array}$ & 414.777 & 135.897 & 622.055 & 111.039 & -7.087 & 0 & -265.612 & -148.942 \\
\hline
\end{tabular}

\section{Results}

Gender was taken as demographic variable. Males were $47.2 \%$ whereas females were $52.8 \%$ of the entire sample. Paired sample $t$ test used to calculate between group difference of Bite Force which was found to be significant $(t=2.895, \mathrm{P}=.005)$. The mean score of Bite force from right side of the mouth was $593.569 \pm$ 136.587 whereas Bite force from right side of the mouth mean score was $518.416 \pm 161.475$.

The results of independent sample $t$ test revealed a significant difference between the handedness and the average force bite from left side of mouth $(t(2,68)=-3.08, \mathrm{P}=.003)$. The mean value of average bite force of left side of mouth for right handed participants was $498.25 \pm 171.90$ which was found to be less as compared to the mean value of average bite force of left side of mouth for left handed participants $614.49 \pm 143.54$.

Moreover, the results for the comparison of average bite force from right side of mouth and handedness was also found significant $(t(2,68)=2.36, \mathrm{P}=.02)$. The mean value of average bite force of right side of mouth for right handed participants was $601.57 \pm 171.09$ which was found to be greater than the mean value of average bite force of right side of mouth for left handed 
participants $503.28 \pm 179.03$.

\section{Discussion}

This study aimed to determine mean maximum bite force in a healthy population with normal occlusion. The study explored the difference of handedness with the bite force which was found to be significant. The results explained that right handed people have higher bite force at right side of mouth on chewing whereas left handed people apply more force while biting with left side of mouth as compared to right side.

Bite force is a complex outcome of multiple factors [1-4, 13, 18, 19] therefore bite force is a unique feature of every human which varies from person to person and age to age. NO two studies till date have reported exactly same bite force values. The disparity between different studies is from $189 \pm 78 \mathrm{~N}$ by Sasaki et al 2019, 89 to $720 \mathrm{~N}$ by Gibbs et al in 1981. Gibbs et al., [21] in 1986 discovered one individual who had a biting force of $4340 \mathrm{~N}$ (443 $\mathrm{kg}$ ). This disparity in the bite force in this study and all the previous studies can be due to various intra human and inter human reasons one of them may the global variation of food preference, food availability, human races environmental factors and human development environment.

The bite force calculated in this study is lower than Sathyanarayana H P, Sridhar Premkumar S [22] with Adults (17-25years) who had a mean MVBF of $601.83 \mathrm{~N}$ with males having a value of $650.67 \mathrm{~N}$ and females it was $543 \mathrm{~N}$. Similarly, with the results of the study done by Bonakdarchian M, Askari N Askari M [4] on a sample of 40 subjects with normal dentition with age range from 19 - 27 years the Mean MVBF is $631.12 \mathrm{~N} \pm 235 \mathrm{~N}$.

The main reason of MVBF calculated in this study being less than that of few other studies may be attributed to the age group taken. In this study the age range is 13 - 40 while in above mentioned other studies the age range is smaller. Relatively younger age group is taken which have been proven to have higher average bite force values than older adults [1, 2, 8-13].

The MVBF calculated in this study is greater thanPalinkasM et al [2] , according to this study average MVBF in age 13-20 years $\mathrm{MVBF}$ is $341.5 \mathrm{~N} \pm 27$, from age $21-30$ years $\mathrm{MVBF}$ is $288.5 \mathrm{~N} \pm$ 24.5, from age 31-40 years MVBF is $264 \mathrm{~N} \pm 21.5$. According to, Al- Saadi D K and , Al - Mulla A A [9], in Iraqi people the MVBF is $392.81 \mathrm{~N} \pm 54.7$. The studies $[2,13]$ with lesser bite force than this study are based on the Brazilian, Iraqi respectively and the studies $[4,12]$ with higher bite force than this study are in based on Irani and Indian population. The results are more comparable to studies $[4,12]$ the reason may be the regional variation as per HallakRegalo S C et al 7 the type of food being consumed in one particular region $[1,2,7]$.

\section{Conclusion}

The study explored the difference of handedness with the bite force which was found to be significant. The results explained that right handed people have higher bite force at right side of mouth on chewing whereas left handed people apply more force while biting with left side of mouth as compared to right side. This was the new finding explored by performing this study.

\section{References}

[1]. Ikebe K, Matsuda K, Kagawa R, Enoki K, Yoshida M, Maeda Y, et al. Association of masticatory performance with age, gender, number of teeth, occlusal force and salivary flow in Japanese older adults: is ageing a risk factor for masticatory dysfunction? Arch Oral Biol. 2011 Oct;56(10):991-6. Pubmed PMID: 21529776.

[2]. PalinkasM,Nassar MSP, Cecı'lio FA, Sie'ssere S, SempriniM,c, Machadode-Sousa JP, et al. Age and gender influence on maximal bite force and masticatory muscles thickness, Arch Oral Biol2010;55:797-802. Pubmed PMID: 20667521.

[3]. Bakke M. Bite force and occlusion. InSeminars in orthodontics.WB Saunders..2006;12:120-6.

[4]. Bonakdarchian M, Askari N, Askari M. Effect of face form on maximal molar bite force with natural dentition. Arch Oral Biol. 2009 Mar;54(3):201-4. Pubmed PMID: 19131047.

[5]. Al-Drees AM. Oral and perioral physiological changes with ageing. Pakistan oral \& dental journal. 2010 Jun 1;30(1).

[6]. Bokhari SA, Khan AA, Ansari JA, Alam R. Tooth loss in institutionalized coronary heart disease patients of Punjab Institute of Cardiology, Lahore, Pakistan. J Epidemiol Glob Health. 2012 Mar;2(1):51-6. Pubmed PMID: 23856398.

[7]. Regalo SCH, Santos CM, Vitti M, Regalo CA, Vasconcelos PB, MestrinerJr $\mathrm{W}$, et al. Evaluation of molar and incisor bite force in indigenous compared with white population in Brazil. arch oral biol 2008;53:282-6.Pubmed PMID:18031710.

[8]. Varga S, Spalj S, Varga ML, Milosevic SA, Mestrovic S, Slaj M. Maximum voluntary molar bite force in subjects with normal occlusion. Eur J Orthod 2011; 33:427-433.Pubmed PMID:21062965.

[9]. Al-Saadi D K and , Al - Mulla A A. Digitalized measurement of maximum bite force in Iraqi adult sample aged $18-25$ years with different malocclusion groups.J BaghColl Dentistry 2011; 23(sp. issue):146-150.

[10]. Sakaguchi M, Ono N, Turuta H, Yoshiike J, Ohhashi T. Development of new handy type occlusal force gauge. Japanese journal of medical electronics and biological engineering 1996; 34: 53-5.

[11]. Paphangkorakit J, Osborn JW. Effect on human maximum occlusal force of biting on a softer or harder object. Arch Oral Biol 1998;43:833-9.Pubmed PMID: 9821506.

[12]. Van Der Bilt A, Tekamp FA, Van Der Glas HW, Abbink JH. Bite force and electromyograpy during maximum unilateral and bilateral clenching. Eur J Oral Sci. 2008;116:217-222. Pubmed PMID:18471239.

[13]. Koc D, Dogan A, Bek B. Bite Force and Influential Factors on Bite Force Measurements: A Literature Review. Eur J Dent. 2010;4:223-232.Pubmed PMID:20396457.

[14]. Manns A, Miralles R, Palazzi C. EMG, occlusal force and elongation of the masseter muscle under isometric voluntary contractions and variations of vertical dimension. J Prosthet Dent 1979;42:674-82. Pubmed PMID: 292779.

[15]. Paphangkorakit J, Osborn JW. Effect of jaw opening on the direction and magnitude of human incisal occlusal forces. JDent Res 1997;76:561-7. Pubmed PMID:9042078.

[16]. Nawaz MS, Yazdanie N, Faheemuddin M. Rehabilitation of a cystic mixed dentition mandible following marsupialization with a multipurpose acrylic splint acting as a space maintainer and an obturator. J Ayub Med Coll 2011;23(2):177-179.Pubmed PMID: 24800375.

[17]. Ming Su C Yang Y, Hsieh T. Relationship between oral status and maximum bite force in preschool children. J Dent Sci 2009;4(1):32-39.

[18]. Gonçalves TM, de Vasconcelos LM, da Silva WJ, Del Bel Cury AA, Garcia RC. Influence of female hormonal fluctuation on maximum occlusal force. Braz Dent J. 2011;22(6):497-501.Pubmed PMID: 22189646.

[19]. Pereira LJ, Gaviāo MB, Bonjardim LR, Castelo PM, van der Bilt A. Muscle thickness, bite force, and craniofacial dimensions in adolescents with signs and symptoms of temporomandibular dysfunction. Eur J Orthod. 2007 Feb;29(1):72-8. Pubmed PMID: 17290018.

[20]. Sasaki K, Hannam A G, Wood WW. Relationships between the size, position, and angulation of human jaw muscles and unilateral first molar bite force. J Den Research. 1989 Mar;68(3):499-503. Pubmed PMID: 2921394.

[21]. Gibbs CH, Mahan PE, Mauderli A, Lundeen HC, Walsh EK.Limits of human bite strength. J Prosthet Dent.1986;56:226- 229. Pubmed PMID: 3463748 .

[22]. Sathyanarayana HP, Premkumar S. Assessment of maximum voluntary bite force in children and adults with normal occlusion. International Journal of Pharmacutical Science and Health Care. 2012;2:64-70. 